\title{
MESSAGES FROM THE OTHER SIDE: PARASITES RECEIVE DAMAGE CUES FROM THEIR HOST PLANTS
}

\author{
MUVARI CONNIE TJIURUTUE ${ }^{1, *}$ \\ ${ }^{1}$ Biology Department, University of Massachusetts Amherst \\ 221 Morrill Science Center South, 611 North Pleasant Street \\ Amherst, MA 01003 \\ Phone: +264 61206 3465; Fax: +264 612063791 \\ connie.muv@gmail.com \\ PHILIP C. STEVENSON ${ }^{2}$ \\ ${ }^{2}$ Natural Resources Institute, University of Greenwich \\ Central Avenue, Chatham Maritime, Kent ME4 4TB, United Kingdom and \\ Royal Botanic Gardens, Kew, Richmond TW9 3AB, UK
}

LYNN S. ADLER ${ }^{1}$ 
Abstract- As sessile organisms, plants rely on their environment for cues indicating imminent herbivory. These cues can originate from tissues on the same plant or from different individuals. Since parasitic plants form vascular connections with their host, parasites have the potential to receive cues from hosts that allow them to adjust defenses against future herbivory. However, the role of plant communication between hosts and parasites for herbivore defense remains poorly investigated. Here we examined the effects of damage to lupine hosts (Lupinus texensis) on responses of the attached hemiparasite (Castilleja indivisa), and indirectly, on a specialist herbivore of the parasite, buckeyes (Junonia coenia). Lupines produce alkaloids as defenses against herbivore that can be taken up by the parasite. We found that damage to lupine host plants by beet armyworm (Spodoptera exigua) significantly increased jasmonic acid (JA) levels in both the lupine host and parasite, suggesting uptake of phytohormones or priming of parasite defenses using host cues. However, lupine host damage did not induce changes in alkaloid levels in the hosts or parasites. Interestingly, the parasite had substantially higher concentrations of JA and alkaloids compared to lupine host plants. Buckeye herbivores consumed more parasite tissue when attached to damaged compared to undamaged hosts. We hypothesize that increased JA due to lupine host damage induced higher iridoid glycosides in the parasite, which are feeding stimulants for this specialist herbivore. Our results demonstrate that damage to hosts may affect both parasites and associated herbivores, indicating cascading effects of host damage on multiple trophic levels.

Key Words- Alkaloids, herbivory, parasitism, plant communication, plant-plant interactions, performance, phytohormones. 


\section{INTRODUCTION}

Plants can prime herbivore defenses in response to compounds released from other tissues within the same individual, or by responding to volatile cues released by damaged neighbors (Karban and Baldwin 1997; Karban et al. 2006; Karban et al. 2014). For example, sagebrush (Artemisia tridentata) experienced reduced herbivory after exposure to volatiles from clipped conspecific neighbors (Karban et al. 2006). Moreover, plants can "eavesdrop" on cues released by conspecifics (Karban et al. 2013). For example, wild tobacco (Nicotiana attenuata) had higher induced defenses and less herbivory when growing next to clipped compared to unclipped sagebrush (Karban et al. 2000). Thus, cues from neighboring plants may provide important information that allows plants to defend against likely attack.

Parasitic plants can acquire nutrients (Phoenix and Press 2005) and defensive compounds from their host via haustorial connections (Adler and Wink 2001; Cabezas et al. 2009; Lehtonen et al. 2005). Due to the close physical proximity and vascular connections between parasitic plants and hosts, parasitic plants could receive chemical cues associated with herbivory indirectly via released volatiles from damaged host plants, or directly via uptake of phytohormones or defensive compounds from hosts. Induced host volatiles could be perceived by neighboring parasites, priming defensive responses. If parasites take up induced phytohormones or chemical defenses from damaged hosts through vascular connections, this could increase the parasite's own resistance to herbivory and reduce parasite damage. For example, Castilleja indivisa hemiparasites grown with Lupinus albus hosts containing high alkaloid levels experienced less herbivory, higher pollinator visits and higher seed set compared to parasites grown with 
low alkaloid hosts (Adler et al. 2001). High pollinator visits were due to reduced damage to flower buds, which resulted in more open flowers that attracted more pollinators (Adler et al. 2001). Thus, uptake of defensive compounds from hosts can influence parasite reproduction.

Although several studies have examined the effects of alkaloid-producing hosts on herbivores of parasites (Adler 2002; Marvier 1996; Marvier 1998; Stermitz et al. 1989), the question of whether host damage mediates interactions between parasites and their herbivores has not been explored. Herbivore-induced host responses could alter parasite species interactions, leading to dynamic changes in food web and community structure (Stam et al. 2014). Moreover, metabolite uptake from the host to the parasite may have implications for biocontrol management of parasitic weeds, since biocontrol species would need to tolerate both the host and parasite defenses (Smith et al. 2013). Findings from these studies may have both ecological and agricultural implications by helping us understand the mechanisms that mediate interactions between hosts, parasites, and herbivores.

The hemiparasite Castilleja indivisa (Orobanchaceae; hereafter Indian paintbrush) and host Lupinus texensis (Fabaceae; hereafter lupine) were used to study the effects of host damage and secondary metabolite uptake on herbivory in the parasite. Lupine is a native, common annual species in Texas that frequently grows and flowers with Indian paintbrush (Loughmiller et al. 1984). Indian paintbrush is an annual root hemiparasite endemic to Texas (Kuijt 1969; Loughmiller et al. 1984) that does not make its own alkaloids, but takes up the alkaloid lupanine when parasitizing lupine hosts (Adler 2000). The parasite, however, produces iridoid glycosides as herbivore defense compounds 
(Stermitz and Pomeroy 1992). Junonia coenia (Lepidoptera: Nymphalidae), or buckeye butterfly, is a specialist herbivore that feeds on plants that produce iridoid glycosides (Bowers 1984), including Castilleja species (Adler 2000). Iridoid glycosides act as feeding and oviposition stimulants (Bowers 1984) and also make the herbivores unpalatable to predators (Theodoratus and Bowers 1999).

To examine the effects of damage on host defenses, parasite defenses and parasite herbivory, we conducted a greenhouse study to ask:

1. Does herbivory to lupine host plants induce changes in phytohormones and alkaloid levels in both lupine hosts and attached parasites?

2. Does herbivory to lupine hosts reduce herbivore performance on attached parasites?

\section{METHODS AND MATERIALS}

Experimental design. Each replicate pot contained 2 lupine hosts and one parasite, because one lupine host is insufficient to support parasite growth through flowering (LSA, pers. obs.). The experiment had 60 replicate pots $x$ two treatments (damage vs non-damaged hosts), for a total of 120 pots. We did not confirm that the parasite was attached to both hosts, but both lupine hosts in the damage treatment were always damaged (data not shown). Thus, the parasite would have received induced signals whether it was attached to one or both hosts. 
Plant propagation. Lupine seeds were purchased from Seedville USA (Massillon, Ohio, USA) and Indian paintbrush seeds were purchased from Native American Seed (Junction, Texas, USA). Lupine seeds were scarified by soaking in concentrated sulfuric acid for 3 hours, followed by rinsing with tap water. Lupine seeds were then transferred to petri dishes lined with moistened filter paper and sealed with parafilm until germination. Germinated seedlings were soaked in a rhizobium inoculant (Gourmet Seed International, Tatum, New Mexico, USA) before planting into 24-cell plugs in Black Gold seeding germination mix (Sun Gro Horticulture, Agawam, MA, USA). Once seedlings established roots, they were repotted into $10 \mathrm{~cm}$ pots in a 1:1 Fafard professional potting mix: course vermiculite (Conrad Affairs, Inc, Agawam, MA, USA; Whittemore Company Inc, Lawrence MA, USA) on 30 May 2014. Lupines were repotted into $50 \mathrm{~cm}$ pots with 2 hosts per pot on 02 July 2014 , and kept in the greenhouse at $65^{\circ} \mathrm{C}$ constant temperature.

Indian paintbrush seeds were germinated in 72-cell trays with Black Gold seedling germination mix moistened with tap water. Seeds were sprinkled on top of soil and covered with plastic wrap to maintain moisture on 29 June 2014, and placed in a growth chamber with mean temperatures of $18^{\circ} \mathrm{C}$ and 16:8 D:N. The seeds were sprayed with tap water as necessary to stay moist. Once seedlings germinated, the tray plugs were transferred to the greenhouse with $65^{\circ} \mathrm{C}$ constant temperature. Seedlings were transplanted on 30 August 2014 into pots with 2 lupine hosts. Once established, seedlings were thinned to one per pot by clipping extra parasites at soil level to avoid disturbing roots. 
Induction experiment. Due to parasite mortality, 54 of the original 60 pots were used to assess host defense induction and compound uptake by the parasite. Each pot contained 2 lupine hosts and one parasite. In half of the pots, host plants were bagged with third instar beet armyworm larvae (Spodoptera exigua; Benzon Research Inc, Carlisle, PA). Larvae were reared on artificial diet of soy flour $(39.0 \mathrm{~g} / \mathrm{l})$ and wheat germ $(34.0 \mathrm{~g} / \mathrm{l})$ and kept in the laboratory at room temperature before the experiment. Control hosts were bagged at the same time without herbivores. Larvae were allowed to feed on plants for 48 $\mathrm{hr}$. In the congeners L. albus and angustifolius, $72 \mathrm{hr}$ of herbivore feeding was sufficient to induce alkaloids (Vilarino et al. 2005), and 20\% mechanical damage also induced alkaloid production (Chludil et al. 2009). Approximately 30\% of plant leaves had some damage, and both hosts were always damaged. Leaf tissue was then collected from both host and parasite for analysis of phytohormones and alkaloids. Leaves were cut from both parasite and lupine at the petiole using a razor blade, which is less likely to induce host responses (Thaler et al. 2010), and immediately placed in liquid nitrogen before storage at $-80^{\circ} \mathrm{C}$ until phytohormone analysis. The remaining leaf tissue from both host and parasite was collected for alkaloid analysis, placed in separate paper bags, and dried at $45^{\circ} \mathrm{C}$ for one week. Due to insufficient leaf material, we pooled parasite leaves for a total of 10 samples ( 5 x 2 treatments) just for the alkaloid analysis. Host leaves were not pooled (54 samples; 27 x 2 treatments).

Phytohormone analysis. We measured leaf jasmonic acid (JA), salicylic acid (SA) and abscisic acid (ABA) hormone levels from damaged and control lupine hosts and attached parasites using a subsample of 15 plants per treatment for both the host and parasite, for a 
total of 60 samples. Phytohormone extraction and analysis were based on Thaler et al. (2010). About 200-300 mg of frozen leaf tissue was transferred into a $2 \mathrm{ml}$ screw cap tube containing pre-weighed 0.9 g silica beads (BioSpec, Bartelsville, OK, USA) and leaves were crushed into small particles inside the tubes. We added $100 \mu \mathrm{l}$ of d4-SA and d5-JA (800 $\mathrm{pg} \mathrm{m}^{-1}$ each) as internal standards (CDN Isotopes, Point-Claire, Canada) with $1 \mathrm{ml}$ extraction buffer (iso-propanol:water:hydrochloric acid 2:1:0.005 by volume) and homogenized the tissue in a FastPrep homogenizer (MP Biomedicals, Solon, Ohio, USA) at $6 \mathrm{~m} / \mathrm{s}$ for 45 seconds. Samples were centrifuged at $4{ }^{\circ} \mathrm{C}$ for $20 \mathrm{~min}$ at $20,800 \mathrm{x} \mathrm{g}$ $(14,000 \mathrm{rpm})$. The supernatant of each sample was carefully transferred into a fresh $2 \mathrm{ml}$ tube, added $1 \mathrm{ml}$ of dichloromethane and vortexed for $30 \mathrm{~min}$. We then centrifuged the samples again at $4{ }^{\circ} \mathrm{C}$ for $20 \mathrm{~min}$ at $12,000 \mathrm{x}$ g for $2 \mathrm{~min}$ for phase separation. The separated aqueous (top) and middle layer were completely removed and discarded before evaporation of samples overnight under a fume hood. Samples were dissolved in $200 \mathrm{ml}$ methanol and filtered through a $0.45 \mu \mathrm{m}$ syringe filter $(13 \mathrm{~mm}$ diam $)$ into $2 \mathrm{ml}$ HPLC vial with insert. This remaining $15 \mu \mathrm{l}$ solvent was analyzed on a triple-quadrupole LCMS/MS system (Quantum Access; Thermo Scientific, Waltham, Massachusetts, USA). A

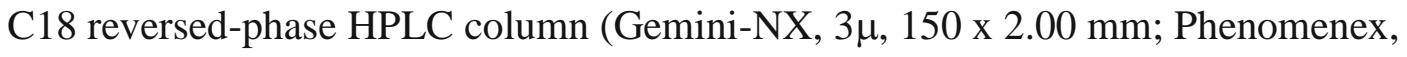
Torrance, California, USA) was used to separate compounds using a solution of $0.1 \%$ formic acid in water (solvent $\mathrm{A}$ ) and $0.1 \%$ formic acid in acetonitrile (solvent B) at a flow rate of $300 \mu \mathrm{l} / \mathrm{min}$. Separation of compounds were performed using a gradient of increasing solvent B content. The initial gradient of solvent B was maintained at $10 \%$ for $2 \mathrm{~min}$ and then increased linearly to $100 \%$ at $20 \mathrm{~min}$. Phytohormones were analyzed using negative electrospray ionization (spray voltage: $3.5 \mathrm{kV}$; sheath gas: 15; auxiliary 
gas: 15 ; capillary temperature: $350^{\circ} \mathrm{C}$ ), collision-induced dissociation (argon CID gas pressure 1.3 mTorr [1.3 micron $\mathrm{Hg}$ ], CID energy $16 \mathrm{~V}$ ) and selected reaction monitoring (SRM) of compound-specific parent/product ion transitions: SA 137 $\rightarrow$ 93; d4-SA $141 \rightarrow 97 ;$ JA 209 $\rightarrow$ 59; d5-JA 214 $\rightarrow 62$ (Thaler et al. 2010).

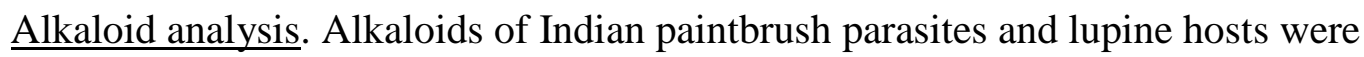
extracted as described in Adler (2000). Briefly, leaves were dried at $45^{\circ} \mathrm{C}$ for one week in the incubator. Dried leaves were then ground using a Wiley Mill (Thomas Scientific, Swedesboro, N.J.) with a 40-mesh screen. Extraction of alkaloids was achieved by adding 0.5 M HLC to approximately $0.5 \mathrm{~g}$ of dry weight for each sample and vortexed until all leaf tissue was covered in solution. Following this, samples were sonicated for $10 \mathrm{~min}$ and left to stand for $1 \mathrm{hr}$ before sonicating again for another $10 \mathrm{~min}$. About $3 \mathrm{ml}$ of $\mathrm{NaOH}$ was added to separate out alkaloids as free bases. The samples were then filtered through extrelut columns (Extrelut NT 20 ml, item number 115096; EMD Milipore Corporation, Darmstadt, Germany) filled with hydromatrix (Agilent technologies Inc., California, USA). About $30 \mathrm{ml} \mathrm{CH}_{2} \mathrm{Cl}_{2}$ was added to each of the extrelut columns and collected into small pre-labeled beakers. The collected filtrates were allowed to dry overnight in the fume hood. About $2 \mathrm{ml}$ of $\mathrm{CH}_{2} \mathrm{Cl}_{2}$ was added to the beakers to re-dissolve the dried filtrate before transfer to a $2 \mathrm{ml} \mathrm{GC}$ vial and left to dry overnight. Plant extracts were redissolved in $1 \mathrm{ml}$ of methanol containing $500 \mu \mathrm{g}$ of dodecyl acetate as an internal standard. The samples were diluted further 100x in methanol before analysis using an Agilent 6890 gas chromatograph fitted with a DB-5 fused silica capillary column (30 m length, $0.25 \mathrm{~mm}$ diameter, $0.25 \mu \mathrm{m}$ film thickness, Agilent Technologies LDA, 
Stockport, Cheshire, UK) and coupled to an Agilent 5973 mass spectrometer. Carrier gas was helium at a constant flow rate of $1 \mathrm{ml} / \mathrm{min}$. The column temperature was held at $60^{\circ} \mathrm{C}$ for $2 \mathrm{~min}$, and then programmed to $240^{\circ} \mathrm{C}$ at $6^{\circ} \mathrm{C} / \mathrm{min}$. Compounds were identified and quantified using the NIST Mass Spectral Database and by comparison to a commercial standard of lupanine (Sigma-Aldrich Company Ltd, Dorset SP8 4XT, UK).

Larval performance experiment. To determine whether host damage affects herbivores on parasites, a total of 54 pots, each containing 2 lupine hosts and one parasite, was used to assess insect performance on the parasite in a no-choice assay. Host plants were damaged with generalist beet armyworm as described earlier. After removal of larvae from host plants, leaves were collected from parasites attached to damaged versus non-damaged hosts plants. Leaves were placed in Petri dishes lined with moistened filter paper containing pre-weighed $2^{\text {nd }}$ instar specialist buckeye larvae (Junonia coenia; Shady Oak Butterfly Farm, Inc., Brooker, Florida, USA) that were allowed to feed on leaves from a single parasite for 24 hours. Buckeyes were fed on Plantago lanceolata leaves before the experiment, deprived of food for 12 hours and then weighed prior to the trial. After 24 hours of feeding, larvae were removed and weighed. Relative growth rate $(\mathrm{RGR}=$ [final wet weight - initial wet weight]/initial wet weight) and dry and proportional amounts of leaves consumed were used as measures of larval consumption and performance.

\section{Statistical analysis}

R for Macintosh version 3.2.1 (R Core Team 2014) was used to carry out all statistical analyses. 
Induction experiment. We ran three separate MANOVAs, one for parasite phytohormone responses and two separate MANOVAs for host and parasite alkaloid responses. For host phytohormones, JA residuals were not normally distributed, and so we used separate ANOVAs for SA and ABA responses, and used the Kruskal-Wallis rank sum test for host JA responses. Each analysis included damage treatment as the independent fixed factor. Responses for phytohormones were JA, SA and ABA, and responses for alkaloids were lupanine, 13-oxolupanine, 17-hydroxylupanine and one unknown lupanine compound; these were the only alkaloids detected in samples.

Significant MANOVAs were followed by one-way ANOVAs. All data were tested for normality prior to analysis and we log-transformed host and parasite alkaloid responses to improve normality of residuals. We excluded 2 parasite outliers from the damage treatment from all analyses (12SD and 5SD above mean for JA) to improve normality of residuals; including these outliers did not qualitatively change the results. Larval performance. We analyzed larval performance using ANOVA with larval RGR as the response and damage treatment as a fixed independent factor. At first we included parasite leaf mass as a covariate, but it was not significant and was removed from the model. We excluded two samples that were compromised during handling, one each from the control and damage treatments. We also analyzed larval consumption as the dry weight of tissue consumed and the proportion of leaves consumed. We included the latter measure because some larvae consumed all leaf tissues, and so might have consumed more if it had been available. We used separate ANOVAs with dry weight of leaves consumed and proportion of leaves consumed as responses, and damage treatment as an independent fixed factor. We excluded one outlier from proportion of leaves consumed 
(4SD below the mean in the damage treatment) that violated assumptions of normality; including this outlier would result in a treatment effect of $P=0.06$ compared to $P=0.04$.

\section{RESULTS}

\section{Induction experiment}

Phytohormones. JA levels increased by $\sim 58 \%$ in damaged host plants compared to controls (Kruskal-Wallis: $\mathrm{df}=1, \chi^{2}=8.93, P=0.0028$; Figure 1 A), but there was no effect of damage on host SA or ABA $\left(F_{1,28}<0.25, P>0.62\right.$ for both; Online Resource 1 , Figure S1). Host damage affected parasite hormone levels (MANOVA, Pillai's trace = $\left.0.32, F_{1,26}=3.72, P=0.025\right)$. In parasites, JA levels more than tripled when attached to damaged vs. control hosts $\left(F_{1,26}=6.20, P=0.020\right.$; Figure1B). Damage did not affect parasite $\mathrm{SA}$ or $\mathrm{ABA}\left(F_{1,26}<1.88, P>0.18\right.$ for both; Online Resource 1 , Figure $\left.\mathrm{S} 1\right)$. The parasite also had JA levels 5 to 10 times higher than host JA levels (compare Figure 1A and $1 \mathrm{~B})$.

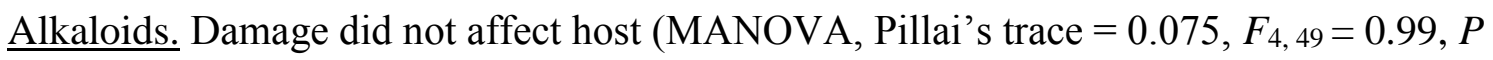
$=0.42$ ) or parasite alkaloid levels (MANOVA, Pillai's trace $=0.57, F_{4,5}=1.64, P=0.30$; Figure 2). Although the parasite does not produce alkaloids, it had substantially higher levels of alkaloids than hosts. Parasite levels of the dominant alkaloid lupanine (Figure 2) and the alkaloid oxolupanine (Online Resource 1, Figure S2) were 6-8 times higher than host levels. 
Larval performance experiment. Larvae consumed a higher proportion of parasite leaves from damaged compared to undamaged hosts $\left(F_{1,47}=4.39 ; P=0.042\right.$; Figure $\left.3 \mathrm{~A}\right)$ but there was no significant difference in dry weight consumed $\left(F_{1,49}=0.47 ; P=0.50\right)$ or larval RGR $\left(F_{1,49}=0.59, P=0.45\right)$, even though RGR was doubled for caterpillars consuming parasites attached to damaged vs. control hosts (Figure 3B).

\section{DISCUSSION}

Does herbivory induce changes in phytohormones and alkaloid levels in both lupine hosts and attached parasites?

Damage to lupine hosts increased JA levels by $\sim 50 \%$ in hosts and by $\sim 320 \%$ in attached parasites (Figure 1A \& B). This suggests that parasites are either taking up host JA or using host cues to prime their own defenses against herbivory. Host cues could include release of volatiles that are perceived by the parasite due to close physical proximity, as has been found for wild tobacco plants near damaged sagebrush (Karban et al. 2000). A few previous studies have examined the uptake of phytohormones by parasitic plants from their hosts. Tomato plants sequentially increased JA and SA levels in response to dodder (Cuscuta pentagona) parasitism, but there was no increase in these hormones in dodder collected from the site of infection (Runyon et al. 2010). In a separate study, caterpillar damage increased JA in tomato hosts, but not in attached dodder parasites (Runyon et al. 2008). This suggests that Cuscuta do not respond to or passively take up phytohormones from their hosts, or that host compounds are degraded before reaching the parasite in that system. To our knowledge, ours is the first study to demonstrate that host damage can increase parasite JA. Future work should be done in a 
greater range of parasitic plant systems to assess the generality of this result, and to dissect whether increased parasite JA is due to direct uptake of host signals or induction due to perception of host volatiles. Induced defenses can structure herbivore preference and performance, and alter herbivore community composition and structure (Agrawal 1999; Poelman et al. 2008; Thaler et al. 2001). Thus, increased JA in attached parasites due to host damage could influence other species interacting with the parasite as well as host.

The assimilation of host alkaloids by parasitic plants has been shown in several parasite taxa including Cuscuta, Castilleja, Pedicularis, Tristerix, Loranthus and Orobanche, and phenolic and cardenolide transfer has been shown in Cuscuta, Santalum and Nerium species (Smith et al. 2013). However, it is not known whether the parasite takes up more defenses in response to host damage in these systems. In our study, we found no effect of host damage on alkaloid levels for either host or parasite. Quinolizidine alkaloids are typically inducible compounds (Chludil et al. 2013; Wink 1983), but may accumulate after more than 48 hours. For example, in other Lupinus species, alkaloid induction occurred 72 hours after damage (Vilarino et al. 2005). Alternatively, beet armyworm used to damage hosts may not elicit a strong defense response in lupines. Although damage did not affect alkaloid levels, parasites had consistently higher levels of alkaloids than their hosts (Figure 2). This could be a mechanism employed by the parasite to obtain host defenses for protection from imminent herbivory. The role of alkaloids in insect defense is well known (Lattanzio et al. 2006; Mithöfer and Boland 2012), and a few studies have shown that secondary metabolite transfer confers benefits to the parasite (Smith et al. 2013). For example, 
Indian paintbrush attached to a high alkaloid lupine genotype had less herbivory, more open flowers, increased pollinator visitation and higher fruit set compared to Indian paintbrush attached to a low alkaloid genotype (Adler 2000, Adler et al 2001). In a more recent study, Rhinanthus serotinus acquired defensive mycotoxins produced by a symbiotic endophytic fungus that lives within a shared grass host (Lehtonen et al. 2005). Parasites grown with endophyte-infected hosts had increased resistance and supported lower aphid performance compared to parasites that were grown with uninfected endophyte hosts. These studies suggest that there could be fitness benefits to parasites that selectively uptake, or increase concentrations of, host-derived defense compounds. Alternatively, high alkaloids in parasites compared to hosts could be a nonadaptive consequence of parasite physiology. This hypothesis is supported by the observation that parasites had higher JA (Figure 1A, B) as well as dominant lupanine (Figure 2) alkaloid concentrations compared to host concentrations. Indian paintbrush and related parasites have a high density of stomata that enables them to maintain a negative water potential in relation to host water potential, allowing the parasite to draw water and nutrients from their host vascular system (Press and Graves 1995). Since Indian paintbrush does not synthesize alkaloids (Stermitz and Pomeroy 1992), it is plausible that the parasite lacks the capacity to degrade these compounds, allowing them to accumulate in the parasite. However, the high levels of JA in the parasite relative to host suggest that other compounds may also become concentrated, either because they are not metabolized quickly or because host-derived JA induces JA production in the parasite. Because alkaloids play major roles in defense against herbivores (Mithöfer and 
Boland 2012), the uptake and concentration of alkaloids by the parasite may exert strong impacts on herbivores and other species that interact with the parasite.

\section{Does herbivory to lupine hosts reduce herbivore performance on attached parasites?}

Herbivores fed on parasites attached to damaged hosts consumed proportionally about 30\% more leaf material compared to controls (Figure 3A). Although not significant, herbivores that fed on parasites attached to damaged hosts also had twice the RGR of herbivores fed on parasites attached to undamaged hosts (Figure 3B). This is surprising because we expected that host damage would induce higher defenses in hosts and attached parasites, reducing herbivore consumption and performance. Furthermore, higher JA in parasites attached to damaged hosts suggests induction of host defenses or assimilation from hosts. However, damage did not affect alkaloid concentrations in hosts or parasites, suggesting that alkaloids are not the mechanism increasing herbivore consumption. Paintbrush parasites produce iridoid glycosides that act as feeding stimulants to buckeye caterpillars (Bowers 1984). One possibility is that JA induced higher levels of iridoid glycosides, increasing herbivore consumption. Unfortunately, we had insufficient parasite leaf material to analyze iridoid glycoside concentrations. It is also possible that other changes occurred due to host damage, such as the release of nutrients due to stress (Karban and Myers 1989; Nykanen and Koricheva 2004). Future studies comparing performance or consumption by both generalist and specialist herbivores may provide mechanistic insights. If both generalist and specialist herbivores consume more of the parasites attached to damaged compared to control hosts, this could indicate increased plant quality. If only the specialist herbivore consumes more of the 
parasite attached to damaged vs control hosts, this suggests induction of iridoid glycosides, which should deter the generalist herbivore. Regardless of the mechanism, host induced responses affected both attached parasites and their associated herbivores.

Changes in host defenses due to damage, and consequences for parasites, could have various outcomes on interacting herbivores and pollinators of both host and parasites. If parasites attached to damaged hosts experience more damage this could lower parasite growth, which may in turn affect other species interacting with these parasites. Additionally, damage could increase production of defenses in the parasite or alter floral traits that could deter pollinators (Erb et al. 2011; Strauss et al. 1999), ultimately reducing parasite reproduction. However, increase in plant defenses could also attract pollinators by reducing floral damage (Adler et al. 2001). In addition, if the host plant and parasite share pollinators due to similarities in floral displays (Moeller 2004), altered visitation to the parasite may also affect host pollination, impacting community dynamics (Callaway 1995; Palmer et al. 2003). Host plants may benefit from herbivory if parasites are consumed more as we found, potentially reducing the impacts of parasitism and increasing host reproduction and survival. This is especially important in agricultural settings, where farmers could simulate herbivory to the host plants by spraying JA (Thaler et al. 2001). Our study provides a clear demonstration of the importance of host responses to damage on parasites and their herbivores, which could impact populations and community composition. Our results further suggest that parasites could use host signals to obtain information about the host's environment, potentially priming their own defenses in anticipation of future herbivory. 
Acknowledgements-Thanks to Adler lab members, D. Chan, L. Ndanga, A. Soleil with plant propagation and data collection, A. Agrawal and A. Kessler labs for help with phytohormone analysis, C. Joyner and colleagues at the UMass CNS greenhouses, Dudley Farman (Nat Res Inst) for help with chemical analysis, and S. McArt and two anonymous reviewers for providing valuable feedback on this manuscript. Thanks to Fulbright Fellowship (MCT), Faculty for the Future Fellowship (MCT), Plant Biology Graduate program (MCT), USDA/CSREES (Hatch) MAS000411 (LSA) and USDA NRI 2008-02346 (LSA) for funding.

Funding: The study was funded by Fulbright Fellowship (MCT), Faculty for the Future Fellowship (MCT), Plant Biology Graduate program (MCT), USDA/CSREES (Hatch) MAS000411 (LSA) and USDA NRI 2008-02346 (LSA).

Conflict of Interest: Author LSA has received recent research grants from USDA-AFRI, NSF-DEB, the North American Pollinator Protection Campaign (co-PI), and the Dartmouth Scholarly Innovation and Advancement Awards (co-PI). All other authors declare that they have no conflict of interest. 


\section{REFERENCES}

Adler LS (2000) Alkaloid uptake increases fitness in a hemiparasitic plant via reduced herbivory and increased pollination. Am Nat 156:92-99

Adler LS (2002) Host effects on herbivory and pollination in a hemiparasitic plant. Ecology 83:2700-2710

Adler LS, Karban R, Strauss SY (2001) Direct and indirect effects of alkaloids on plant fitness via herbivory and pollination. Ecology 82:2032-2044

Adler LS, Wink M (2001) Transfer of quinolizidine alkaloids from hosts to hemiparasites in two Castilleja-Lupinus associations: analysis of floral and vegetative tissues. Biochem Syst Ecol 29:551-561

Agrawal AA (1999) Induced responses to herbivory in wild radish: effects on several herbivores and plant fitness. Ecology 80:1713- 1723

Bowers MD (1984) Iridoid glycosides and host-plant specificity in larvae of the buckeye butterfly, Junonia coenia (Nymphalidae). J Chem Ecol 10:1567-1577

Cabezas NJ, Urzua AM, Niemeyer HM (2009) Translocation of isoquinoline alkaloids to the hemiparasite, Tristerix verticillatus from its host, Berberis montana. Biochem Syst Ecol 37:225-227

Callaway RM (1995) Positive interactions among plants. Bot Rev 61:306-349

Chludil HD, Leicach SR, Corbino GB, Barriga LG, Vilarino MD (2013) Genistin and quinolizidine alkaloid induction in L. angustifolius aerial parts in response to mechanical damage. J Plant Interact 8:117-124 
Chludil HD, Vilarino MD, Franco ML, Leicach SR (2009) Changes in Lupinus albus and Lupinus angustifolius alkaloid profiles in response to mechanical damage. J Agric Food Chem 57:6107-6113

Erb M, Robert CAM, Hibbard BE, Turlings TCJ (2011) Sequence of arrival determines plant-mediated interactions between herbivores. J Ecol 99:7-15

Karban R, Baldwin IT (1997) Induced responses to herbivory. The Univeristy of Chicago Press, London

Karban R, Baldwin IT, Baxter KJ, Laue G, Felton GW (2000) Communication between plants: induced resistance in wild tobacco plants following clipping of neighboring sagebrush. Oecologia 125:66-71

Karban R, Myers JH (1989) Induced plant responses to herbivory. Annu Rev Ecol Syst $20: 331-348$

Karban R, Shiojiri K, Huntzinger M, McCall AC (2006) Damage-induced resistance in sagebrush: Volatiles are key to intra- and interplant communication. Ecology $87: 922-930$

Karban R, Shiojiri K, Ishizaki S, Wetzel WC, Evans RY (2013) Kin recognition affects plant communication and defence. Proc R Soc B-Biol Sci 280:5

Karban R, Wetzel WC, Shiojiri K, Ishizaki S, Ramirez SR, Blande JD (2014) Deciphering the language of plant communication: volatile chemotypes of sagebrush. New Phytol 204:380-385

Kuijt J (1969) The biology of parasitic flowering plants. illustrated edn. University of California Press, Berkeley 
Lattanzio V, Lattanzio VMT, Cardinali A (2006) Role of phenolics in the resistance mechanisms of plants against fungal pathogens and insects. Phytochemistry: Advances in research 661:23-67

Lehtonen P, Helander M, Wink M, Sporer F, Saikkonen K (2005) Transfer of endophyteorigin defensive alkaloids from a grass to a hemiparasitic plant. Ecol Lett 8:12561263

Loughmiller C, Loughmiller La, Sherrod L (1984) Texas Wildflowers : A Field Guide. University of Texas Press, Austin

Marvier MA (1996) Parasitic plant-host interactions: Plant performance and indirect effects on parasite-feeding herbivores. Ecology 77:1398-1409

Marvier MA (1998) A mixed diet improves performance and herbivore resistance of a parasitic plant. Ecology 79:1272-1280

Mithöfer A, Boland W (2012) Plant defense against herbivores: chemical aspects. Annu Rev Plant Biol 63:431-450

Moeller DA (2004) Facilitative interactions among plants via shared pollinators. Ecology $85: 3289-3301$

Nykanen H, Koricheva J (2004) Damage-induced changes in woody plants and their effects on insect herbivore performance: a meta-analysis. Oikos 104:247-268

Palmer TM, Stanton ML, Young TP (2003) Competition and coexistence: Exploring mechanisms that restrict and maintain diversity within mutualist guilds. Am Nat 162:S63-S79 
Phoenix GK, Press MC (2005) Linking physiological traits to impacts on community structure and function: the role of root hemiparasitic Orobanchaceae (exScrophulariaceae). J Ecol 93:67- 78

Poelman EH, Broekgaarden C, Van Loon JJA, Dicke M (2008) Early season herbivore differentially affects plant defence responses to subsequently colonizing herbivores and their abundance in the field. Mol Ecol 17:3352-3365

Press MC, Graves JD (1995) Parasitic Plants. First edn. Chapman \& Hall, 2-6 Boundary Row, , London SE1 8HN, UK

R: A language and environment for statistical computing (2014) R Foundation for Statistical Computing. Reference Source.

Runyon JB, Mescher MC, De Moraes CM (2008) Parasitism by Cuscuta pentagona attenuates host plant defenses against insect herbivores. Plant Physiol 146:987995

Runyon JB, Mescher MC, Felton GW, De Moraes CM (2010) Parasitism by Cuscuta pentagona sequentially induces JA and SA defense pathways in tomato. Plant Cell Environ 33:290-303

Smith JD, Mescher MC, De Moraes CM (2013) Implications of bioactive solute transfer from hosts to parasitic plants. Curr Opin Plant Biol 16:464-472

Stam JM, Kroes A, Li YH, Gols R, van Loon JJA, Poelman EH, Dicke M (2014) Plant interactions with multiple insect herbivores: From community to genes. Annual Review of Plant Biology, Vol 65 65:689-713

Stermitz FR, Belofsky GN, Ng D, Singer MC (1989) Quinolizidine alkaloids obtained by Pedicularis-semibarbata (scrophulariaceae) from Lupinus-fulcratus 
(leguminosae) fail to influence the specialist herbivore Euphydryas-editha (lepidoptera). J Chem Ecol 15:2521-2530

Stermitz FR, Pomeroy M (1992) Chemistry of the schrophulariaceae .23. Iridoid glycosides from Castilleja purpurea and C. indivisa, and quinolizidine alkaloid transfer from Lupinus texensis to $C$. indivisa via root parasitism. Biochem Syst Ecol 20:473-475

Strauss SY, Siemens DH, Decher MB, Mitchell-Olds T (1999) Ecological costs of plant resistance to herbivores in the currency of pollination. Evolution 53:1105-1113

Thaler JS, Agrawal AA, Halitschke R (2010) Salicylate-mediated interactions between pathogens and herbivores. Ecology 91:1075-1082

Thaler JS, Farag MA, Pare PW, Dicke M (2002) Jasmonate-deficient plants have reduced direct and indirect defences against herbivores. Ecol Lett 5:764-774

Thaler JS, Stout MJ, Karban R, Duffey SS (2001) Jasmonate-mediated induced plant resistance affects a community of herbivores. Ecol Entomol 26:312-324

Theodoratus D, Bowers MD (1999) Effects of sequestered iridoid glycosides on prey choice of the prairie wolf spider, Lycosa carolinensis. J Chem Ecol 25:283-295

Vilarino MD, Mareggiani G, Grass MY, Leicach SR, Ravetta DA (2005) Post-damage alkaloid concentration in sweet and bitter lupin varieties and its effect on subsequent herbivory. J Appl Entomol 129:233-238

Wink M (1983) Wounding-induced increase of quinolizidine alkaloid accumulation in lupin leaves. ZNaturforsch(C) 38:905-909 


\section{Figure legends}

Fig. 1. Damage effects on phytohormone levels in (A) Host JA and (B) parasite JA. Host damage significantly increased JA in both hosts and attached parasites. Note the different y-axis scale for (A) and (B). Different letters above the bars indicate significant differences between treatments within the host or parasite $(P<0.05)$. Error bars represent standard error.

Fig. 2. Effects of damage on lupanine levels of hosts and attached parasites. Different letters above the bars indicate significant differences between treatments within the host or parasite $(P<0.05)$. Error bars represent standard error.

Fig. 3. Differences in herbivore consumption and performance feeding on parasites attached to control and damaged hosts. (A) Proportion of leaves consumed by larvae and (B) relative growth rate (RGR) of larvae. Different letters above the bars indicate significant differences $(P<0.05)$. Error bars represent standard error. 